\title{
Reduction in undiagnosed HIV infection in the European Union/European Economic Area, 2012 to 2016
}

Ard van Sighem ${ }^{1}$, Anastasia Pharris ${ }^{2}$, Chantal Quinten ${ }^{2}$, Teymur Noori², Andrew J Amato-Gauci², the ECDC HIV/AIDS Surveillance and Dublin Declaration Monitoring Networks ${ }^{3}$

1. Stichting HIV Monitoring, Amsterdam, the Netherlands

2. European Centre for Disease Prevention and Control (ECDC), Stockholm, Sweden

3. The members of the networks are listed at the end of the article

Correspondence: Anastasia Pharris (anastasia.pharris@ecdc.europa.eu)

van Sighem Ard, Pharris Anastasia, Quinten Chantal, Noori Teymur, Amato-Gauci Andrew J, the ECDC HIV/AIDS Surveillance and Dublin Declaration Monitoring Networks. Reduction in undiagnosed HIV infection in the European Union/European Economic Area, 2012 to 2016. Euro Surveill. 2017;22(48):pii=17-00771. https:// doi.org/10.2807/1560-7917.ES.2017.22.48.17-00771

It is well-documented that early HIV diagnosis and linkage to care reduces morbidity and mortality as well as HIV transmission. We estimated the median time from HIV infection to diagnosis in the European Union/ European Economic Area (EU/EEA) at 2.9 years in 2016, with regional variation. Despite evidence of a decline in the number of people living with undiagnosed HIV in the EU/EEA, many remain undiagnosed, including $33 \%$ with more advanced HIV infection (CD4<350 cells/ $\left.\mathrm{mm}^{3}\right)$.

HIV remains an important public health issue affecting the 31 countries of the European Union and European Economic Area (EU/EEA) [1]. In 2015, it was estimated that ca 120,000 people (15\% of those living with HIV in the EU/EEA) were living with undiagnosed HIV infection [2]. In order to understand regional variations in (i) HIV incidence, (ii) time to HIV diagnosis, and (iii) the number of people living with undiagnosed HIV, we analysed HIV and AIDS surveillance data from 2003 through 2016.

\section{Calculation of 2016 estimates}

Annually, HIV surveillance data are reported by EU/EEA countries to a database for HIV/AIDS that is coordinated jointly by the European Centre for Disease Prevention and Control (ECDC) and the World Health Organization (WHO) Regional Office for Europe within the European Surveillance System (TESSy) [1].

Countries were grouped into four geographical regions (East, South, West, North) (Figure 1) based on a United Nations definition [3]. For those countries lacking data on $\mathrm{CD}_{4}$ count at diagnosis, the distribution of $\mathrm{CD}_{4}$ count in the region they belonged to was assumed to be representative. When grouping countries, the epidemic characteristics across countries were pooled and a similar probability of diagnosis by $\mathrm{CD}_{4}$ cell count category for all countries within that region was assumed.

Annual data on HIV diagnoses reported to TESSy for 2003-2016 were adjusted for reporting delay and under-reporting. Data were adjusted for non-national coverage of some countries' reporting systems (20032011 for Italy and 2003-2012 for Spain) and cases (3\%) that had been previously reported as diagnosed were excluded. Data were then stratified by the presence of a concurrent AIDS diagnosis and, for people without concurrent AIDS, by CD4 cell count levels at the time of diagnosis i.e. $\geq 500,350-499,200-349,<200$ cells $/ \mathrm{mm}^{3}$ [4]. The 'incidence method' in the European Centre for Disease Prevention and Control (ECDC) HIV Modelling Tool version 1.3.0 was used for each region in 2016 to estimate the (i) HIV incidence, (ii) median time from infection to diagnosis, and (iii) number of people living with HIV who were not yet diagnosed $[5,6]$.

\section{HIV incidence in 2016}

In 2016, 29,444 cases of HIV were diagnosed and reported in the EU/EEA, resulting in a notification rate of 5.9 per 100,000 population when adjusted for reporting delay [1]. Rates in 2010-2015 had ranged from 6.5 to 6.7 and in 2016, for the first time in a decade, there was a clear decline in the rate of new HIV diagnoses at EU/EEA level although rates in 11 of 31 EU/EEA countries have continued to increase. 
Regions used in the analysis of undiagnosed HIV infections, European Union/European Economic Area, 2016

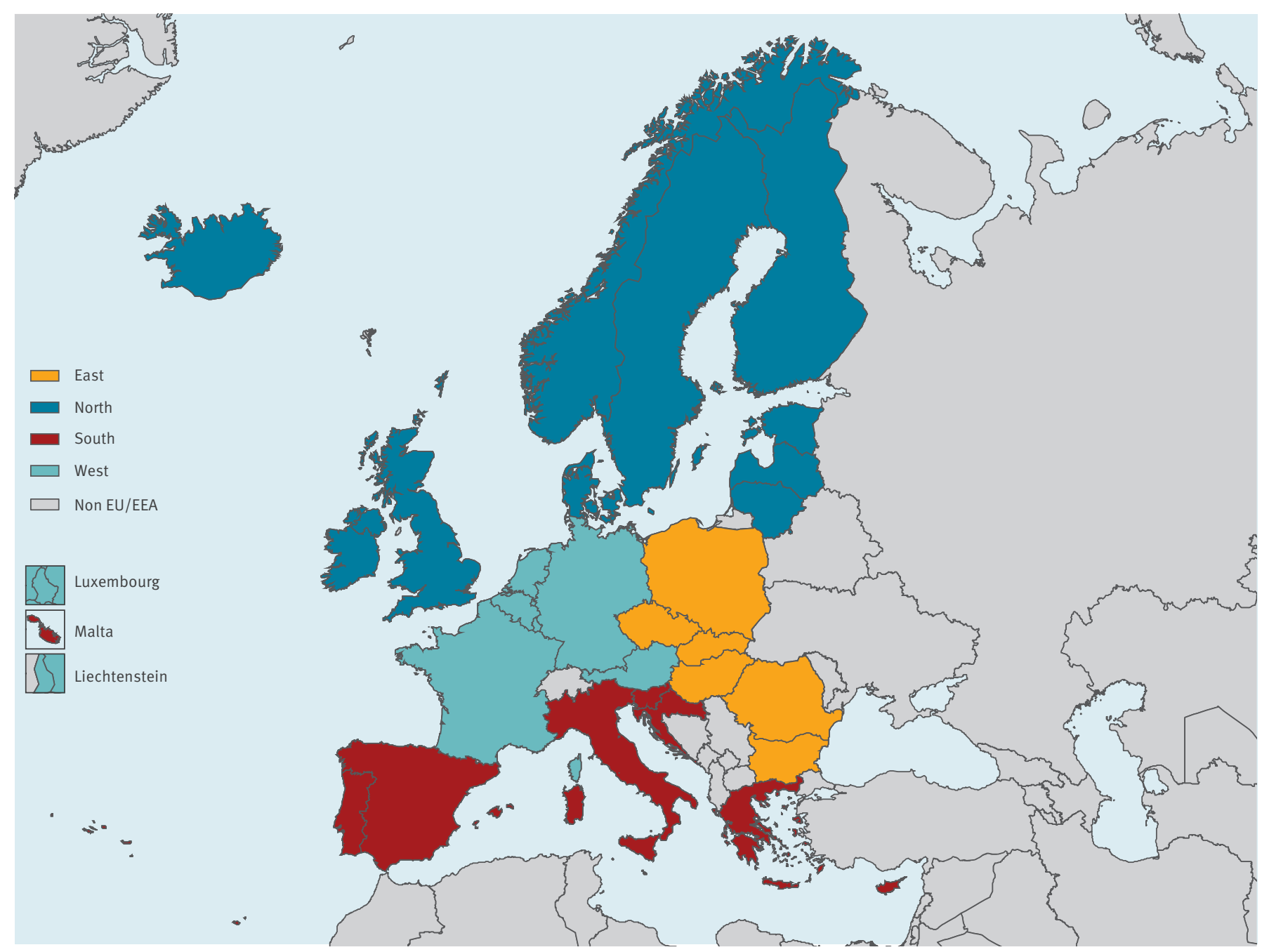

EU/EEA: European Union/European Economic Area.

Countries' grouping based on a United Nations definition [3].

In 2016, the estimated number of new HIV infections (incidence rate) was lower than the number of new diagnoses (notification rate) and was 3.6 per 100,000 population (95\% confidence interval $(\mathrm{Cl})$ : 3.3-4.1) for the EU/EEA overall. This differed substantially between the four regions: the highest estimated incidence rate was in the West $(5.2 / 100,000$ population; $95 \% \mathrm{Cl}: 4.6-$ 5.9) and South (3.8;95\% Cl: $2.8-4.8)$ and it was lower in the North $(2.2 ; 95 \% \mathrm{Cl}: 2.0-3.4)$ and East (1.7; 95\% Cl 1.2-2.2).

\section{Median time from infection to diagnosis}

The median time from infection to diagnosis was estimated to have declined in the EU/EEA overall and in all four regions between 2012 and 2016. In 2016, the EU/EEA median was 2.9 years (interquartile range: $1.4^{-}$ 5.3) with some variation by region: South (3.6 years),
East (3.0 years), West (2.6 years) and North (2.2 years) (Figure 2).

The estimated undiagnosed number of people living with HIV in 2016 was highest in the South and West (38,000 and 36,700 , respectively), compared with 17,500 in the North and 9,100 in the East (Figure 3). Over the period 2012-2016 the number of people estimated to be living with undiagnosed HIV declined in the EU/EEA overall, from an estimated 132,200 in 2012 to 101,400 in 2016 . This decline was observed in all four regions, with a relatively more rapid decline in the South and particularly in recent years in the North. In 2016, this resulted in lower estimated proportions of people living with undiagnosed HIV in the South, North and West $(11.0 \%, 11.3 \%$, and $12.1 \%$, respectively) and a higher proportion in the East (16.8\%). 


\section{FIGURE 2}

Expected median time from HIV infection to diagnosis by year of infection, European Union/ European Economic Area and regions ${ }^{\mathrm{a}}, 2012-2016$

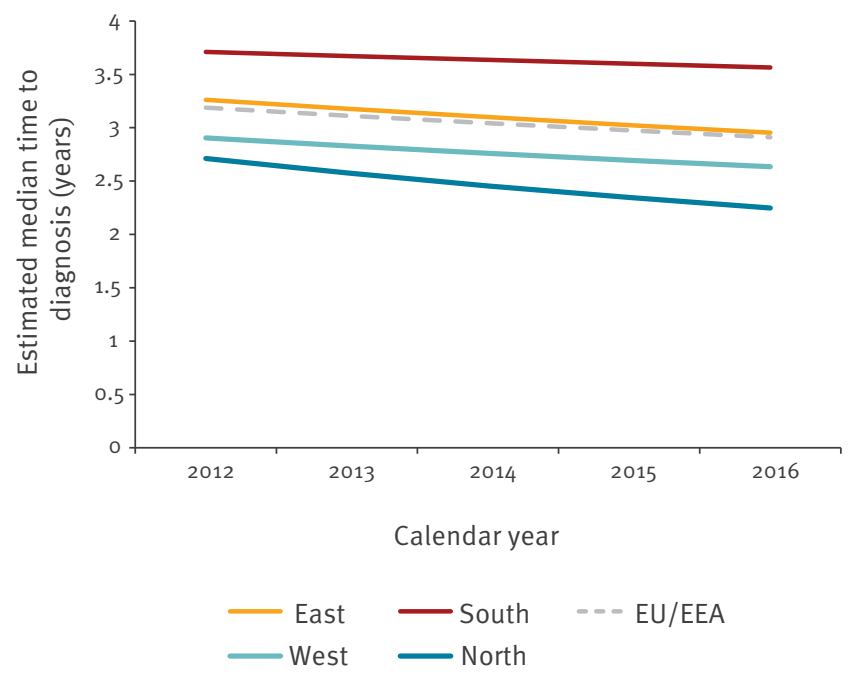

a Countries' grouping based on a United Nations definition [3].

We estimated that $45 \%$ of those living with undiagnosed $\mathrm{HIV}$ in the EU/EEA in 2016 had a CD4 cell count of $>500$ cells $/ \mathrm{mm}^{3}$, which suggests a relatively shorter duration of infection in this group (Figure 4). Conversely, 33\% had an estimated CD4 cell count of $\$ 350$ cells $/ \mathrm{mm}^{3}$, indicating a longer duration of HIV infection. Recency of infection varied by region, with the highest proportion of more recent infections observed in the West (51\%) and the highest proportion of infections of longer duration in the South (37\%).

\section{Discussion and conclusions}

Our analysis provides evidence of a decline in the number of people living with undiagnosed HIV during the last 5 years in the EU/EEA. This decrease was more evident in the South and North regions. This may be associated with observed national-level declines in reported HIV notifications and newly acquired infections, evidence of more frequent testing and earlier diagnosis in some countries [7-10].

With a notification rate of 5.9 per 100,000 population and an estimated incidence of 3.6 per 100,000 , it appears that currently more individuals in the EU/EEA are being diagnosed than are newly infected with HIV. Between 2012 and 2016, the yearly diagnosed fraction (yearly number of new diagnoses/(yearly number of new diagnoses + estimated number of undiagnosed people living with HIV)) increased from $20 \%$ to $23 \%$ [11]. This suggests that testing activities are 'gaining ground' on the hidden epidemic. If our estimates are accurate, if incidence does not increase unexpectedly, and if testing patterns remain stable or increase, this should result in further reductions in the number of undiagnosed people living with HIV and indicate

\section{FIGURE 3}

Estimated number of undiagnosed HIV infections, EU/ EEA and regions ${ }^{\mathrm{a}}, 2012-2016$

\section{A. EU/EEA}

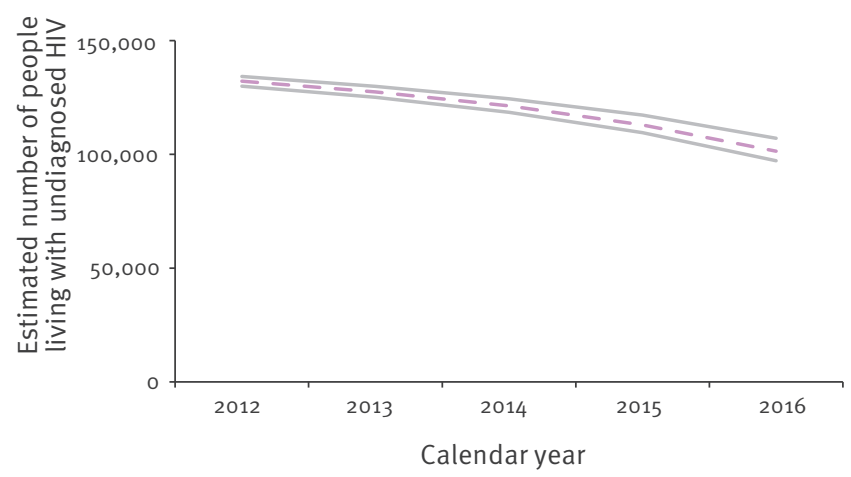

B. Regions ${ }^{\mathrm{a}}$

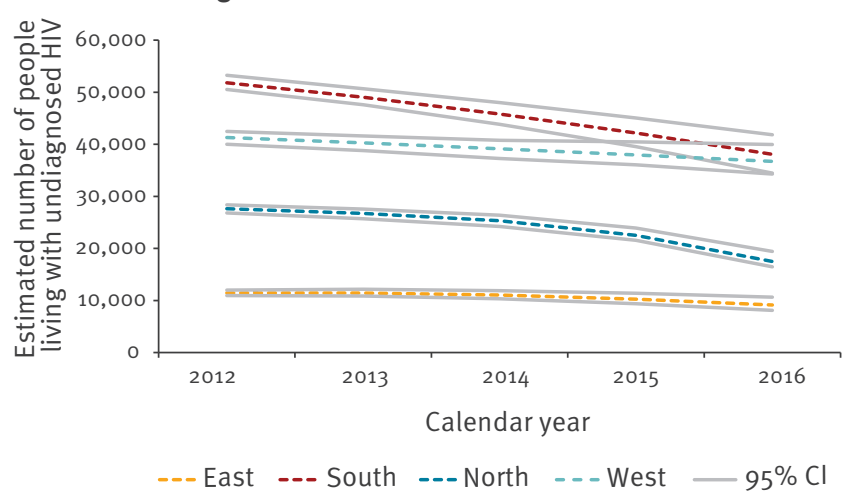

$\mathrm{Cl}$ : confidence interval; EU/EEA: European Union/ European Economic Area.

a Countries' grouping based on a United Nations definition [3].

progress towards achieving the global 2020 target of $90 \%$ of people living with HIV in the EU/EEA being diagnosed [12]. Currently there is heterogeneity across regions with regard to this target, with faster proportional declines in the number of people living with undiagnosed HIV in the South and North regions. The highest proportions of people living with undiagnosed $\mathrm{HIV}$ are in the countries in the East region of the EU/ EEA.

Despite the welcome and positive trend in reduced numbers of undiagnosed infections, we estimated that it takes a median of 2.9 years from infection to diagnosis, and even more than 3 years in some regions of the EU/EEA. Shorter time to diagnosis is well-correlated with a higher $\mathrm{CD}_{4}$ cell count at diagnosis in the various regions; while the reverse is also true. It is well documented that early HIV diagnosis and rapid linkage to antiretroviral treatment for HIV results in lower HIVrelated morbidity and mortality for individuals infected [13], and in reduced HIV transmission at populationlevel [14]. Diversifying and streamlining HIV testing programmes may improve access and uptake. Effective ways of doing this include augmenting routine testing 
FIGURE 4

CD4 cell count in people living with undiagnosed HIV,

EU/EEA and regions ${ }^{\mathrm{a}}, 2016$

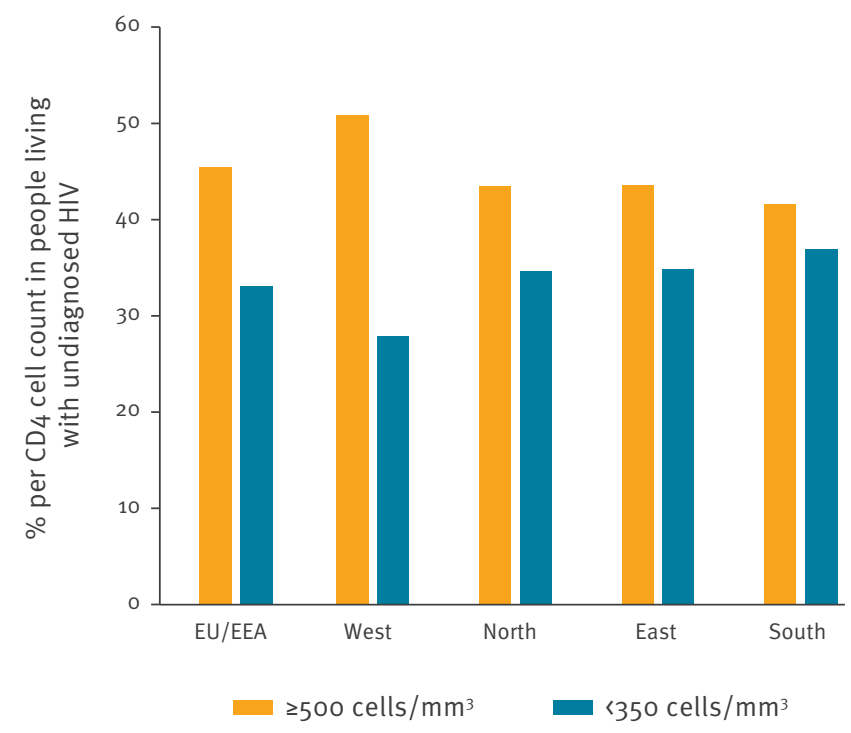

EU/EEA: European Union/ European Economic Area.

a Countries' grouping based on a United Nations definition [3].

for health conditions associated with HIV ('indicator condition-guided testing'), increasing HIV testing during screening for other sexually transmitted infections, and continuing to expand community-based testing, self-testing/home-sampling, and partner notification [15-17].

Our analysis is subject to several important limitations. First, it is based on surveillance data and, while the quality of EU/EEA surveillance data are generally good and continue to improve year-on-year, some countries do not report $\mathrm{CD}_{4}$ cell count at diagnosis. Our assumption that the distribution of $\mathrm{CD}_{4}$ cell count was the same in these countries as for others in the same region could have resulted in less robust estimates by region. Second, the effect of migration on HIV incidence and the undiagnosed number is complex and this was not accounted for in this analysis. Third, there is substantial variation in epidemic patterns within the four regions and overall results for a region cannot be directly applied to the individual countries within it with confidence. Often estimates for the region were heavily influenced by the countries with larger population within the region. Still, our exercise points to the diversity of HIV incidence and in the undiagnosed population across Europe and underlines the need for increased availability of robust national estimates to guide and evaluate testing and prevention practice.

This analysis provides evidence that, although patterns across Europe are diverse, there appears to be a positive trend towards lower numbers of people living with undiagnosed HIV over time. Still, differences across the EU/EEA persist and these trends are not seen to the same extent in all the four regions analysed. We found that a substantial number of people are living with undiagnosed HIV in the EU/EEA, that $33 \%$ of these have more advanced HIV infection, and that the median time from infection to diagnosis is still nearly 3 years. Together this indicates that additional efforts are needed to increase the availability and uptake of HIV testing and rapid linkage to HIV treatment in countries in the EU/EEA.

The ECDC HIV/AIDS Surveillance and Dublin Declaration Monitoring Networks

ECDC HIV/AIDS Surveillance and Dublin Declaration Monitoring Networks include: Austria: Daniela Schmid, Irene Rueckerl, Robert Zangerle; Belgium: Andre Sasse, Dominique Van Beckhoven, Frédéric Denauw; Bulgaria: Tonka Varleva, Vyara Georgieva; Croatia: Tatjana Nemeth Blazic, Jasmina Pavlic, Josip Begovac; Cyprus: Maria Koliou, Linos Hadjihannas, Anna Demetriou; Czech Republic: Marek Maly, Vratislav Němeček, Veronika Šikolová; Denmark: Susan Cowan, Jan Fouchard; Estonia: Kristi Rüütel, AnnaLiisa Pääsukene; Finland: Kirsi Liitsola, Mika Salminen, Henrikki Brummer- Korvenkontio; France: Françoise Cazein, Josiane Pillonel, Florence Lot, Jean- Christophe Comboroure; Germany: Barbara Gunsenheimer-Bartmeyer, Matthias an der Heiden, Gesa Kupfer, Ulrich Marcus; Greece: Vasilios Raftopoulos, Stavros Patrinos, Vasileia Konte; Hungary: Maria Dudas, Katalin Szalay; Iceland: Haraldur Briem, Gudrun Sigmundsdottir; Ireland: Derval Igoe, Kate O’Donnell, Caroline Hurley, Fiona Lyons; Italy: Barbara Suligoi, Anna Caraglia; Latvia: Šarlote Konova; Liechtenstein: Sabine Erne; Lithuania: Irma Čaplinskienė; Luxembourg: Aurelie Fischer, Patrick Hoffmann; Malta: Jackie Maistre Melillo, Tanya Melillo; Netherlands: Eline Op de Coul, Silke David; Norway: Hans Blystad, Arild Johan Myrberg; Poland: Magdalena Rosinska, Iwona Wawer; Portugal: Isabel Aldir, Helena Cortes Martins, Teresa Melo; Romania: Mariana Mardarescu; Slovakia: Peter Truska, Jan Mikas; Slovenia: Irena Klavs; Spain: Asuncion Diaz, Olivier Nuñez, Olivia Castillo; Sweden: Maria Axelsson, Anders Sönnerborg; United Kingdom: Peter Kirwan, Cuong Chau, Sandra Okala, Alison Brown, Valerie Delpech.

\section{Acknowledgements}

We would like to thank Annemarie Stengaard from the WHO Regional Office for Europe; and ECDC colleagues, namely Valentina Lazdina, Phillip Zucs, Denis Coulombier, and Mike Catchpole.

\section{Conflict of interest}

None declared.

Authors' contributions

The ECDC HIV/AIDS Surveillance and Dublin Declaration networks supplied the data and provided comments on the manuscript. All co-authors developed the concept of the manuscript. AvS carried out the modelling analysis. AP wrote the first draft. AP and AvS responded to reviewers' comments. All authors have read and approved the final manuscript.

References 
1. European Centre for Disease Prevention and Control (ECDC)/ World Health Organization (WHO) Regional Office for Europe. HIV/AIDS Surveillance 2017, 2016 data. Stockholm: ECDC; 28 Nov 2017. Available from: https://ecdc.europa.eu/sites/ portal/files/documents/20171127-Annual_HIV_Report_ Cover\%2BInner.pdf

2. Pharris A, Quinten C, Noori T, Amato-Gauci AJ, van Sighem AECDC HIV/AIDS Surveillance and Dublin Declaration Monitoring Networks. Estimating HIV incidence and number of undiagnosed individuals living with HIV in the European Union/European Economic Area, 2015. Euro Surveill. 2016;21(48):30417. https://doi.org/10.2807/1560-7917. ES.2016.21.48.30417 PMID: 27934585

3. United Nations Statistics Division. Standard Country or Area Codes for Statistical Use. In: M, No. 49/Rev.4. Edited by United Nations Statistics Division. New York, NY; 1999.

4. US Centers for Disease Control and Prevention. 1993 revised classification system for HIV infection and expanded surveillance case definition for AIDS among adolescents and adults. MMWR Recomm Rep. 1992;41(RR-17):1-19. PMID: 1361652

5. van Sighem A, Nakagawa F, De Angelis D, Quinten C, Bezemer $D$, de Coul EO, et al. Estimating HIV Incidence, Time to Diagnosis, and the Undiagnosed HIV Epidemic Using Routine Surveillance Data. Epidemiology. 2015;26(5):653-60. https:// doi.org/10.1097/EDE.0000000000000324 PMID: 26214334

6. European Centre for Disease Prevention and Control (ECDC). HIV Modelling Tool. Stockholm: ECDC; 2015. [Accessed 28 Nov 2017]. Available from: https://ecdc.europa.eu/en/ publications-data/hiv-modelling-tool

7. Brown AE, Mohammed H, Ogaz D, Kirwan PD, Yung M, Nash $S G$, et al. Fall in new HIV diagnoses among men who have sex with men (MSM) at selected London sexual health clinics since early 2015: testing or treatment or pre-exposure prophylaxis (PrEP)? Euro Surveill. 2017;22(25):30553. https://doi. org/10.2807/1560-7917.ES.2017.22.25.30553 PMID: 28662762

8. Public Health England (PHE). HIV Testing in England: 2017 report. London: PHE; 2017. Available from: https://www.gov. uk/government/uploads/system/uploads/attachment data/ file/659078/HIV_testing_in_England_report_2017.pdf

9. National Institute for Public Health and Environment (RIVM). Sexually transmitted infections including HIV, in the Netherlands 2016. Bilthoven: RIVM; 2017. Available from: http://www.rivm.nl/dsresource?objectid=7b76e243ca01-40d2-b5od-af67c2aob83f\&type =pdf\&disposition $=$ inli ne

10. Sasse A, Deblond J, Jamine D, Ost C, Van Beckhoven D. Epidemiologie van AIDS en HIV-infectie in Belgie. [Epidemiology of AIDS and HIV infection in Belgium].Edited by (WIV-ISP) WIV. Brussels; 2016. Dutch. Available from: https:// www.wiv-isp.be/sites/www.wiv-isp.be/files/jaarrapport_hiv_ aids_2016_web.pdf

11. Sasse A. Letter to the editor: New metrics to monitor progress towards global HIV targets: using the estimated number of undiagnosed HIV-infected individuals as denominator. Euro Surveill. 2016;21(50): $\mathrm{pii}=30424$. https://doi.org/10.2807/156o7917.ES.2016.21.50.30424

12. The Joint United Nations Programme on HIV/AIDS (UNAIDS). 90-90-90: An ambitious treatment target to help end the AIDS epidemic. Geneva: UNAIDS; 2014. Available from: http://www. unaids.org/sites/default/files/media_asset/90-90-90_en.pdf

13. Lundgren JD, Babiker AG, Gordin F, Emery S, Grund B, Sharma S, et al. Initiation of Antiretroviral Therapy in Early Asymptomatic HIV Infection. N Engl J Med. 2015;373(9):795807. https://doi.org/10.1056/NEJMoa1506816 PMID: 26192873

14. Cohen MS, Chen YQ, McCauley M, Gamble T, Hosseinipour MC, Kumarasamy N, et al. Prevention of HIV-1 infection with early antiretroviral therapy. N Engl J Med. 2011;365(6):493-505. https://doi.org/10.1056/NEJMoa1105243 PMID: 21767103

15. Vriend HJ, Stolte IG, Heijne JC, Heijman T, De Vries HJ, Geskus RB, et al. Repeated STI and HIV testing among HIV-negative men who have sex with men attending a large STI clinic in Amsterdam: a longitudinal study. Sex Transm Infect. 2015;91(4):294-9. https://doi.org/10.1136/ sextrans-2014-051786 PMID: 25504922

16. Joore IK, Arts DL, Kruijer MJ, Moll van Charante EP, Geerlings SE, Prins JM, et al. HIV indicator condition-guided testing to reduce the number of undiagnosed patients and prevent late presentation in a high-prevalence area: a case-control study in primary care. Sex Transm Infect. 2015;91(7):467-72. https:// doi.org/10.1136/sextrans-2015-052073 PMID: 26126531

17. Ferrer L, Loureiro E, Meulbroek M, Folch C, Perez F, Esteve $A$, et al. High HIV incidence among men who have sex with men attending a community-based voluntary counselling and testing service in Barcelona, Spain: results from the ITACA cohort. Sex Transm Infect. 2016;92(1):70-5. https://doi. org/10.1136/sextrans-2015-052042 PMID: 26136507

\section{License and copyright}

This is an open-access article distributed under the terms of the Creative Commons Attribution (CC BY 4.0) Licence. You may share and adapt the material, but must give appropriate credit to the source, provide a link to the licence, and indicate if changes were made.

This article is copyright of the authors, 2017. 